\title{
Pneumatic Formwork Systems in Structural Engineering
}

\author{
Benjamin Kromoser and Patrick Huber \\ Institute for Structural Engineering, TU Vienna, Karlsplatz 13, E212-2, 1040 Vienna, Austria \\ Correspondence should be addressed to Benjamin Kromoser; benjamin.kromoser@tuwien.ac.at \\ Received 17 June 2016; Accepted 10 July 2016 \\ Academic Editor: João M. P. Q. Delgado
}

Copyright (C) 2016 B. Kromoser and P. Huber. This is an open access article distributed under the Creative Commons Attribution License, which permits unrestricted use, distribution, and reproduction in any medium, provided the original work is properly cited.

\begin{abstract}
Concrete as a construction material is characterized by high compressive strength, low tensile strength, and good casting ability. In order to fully utilize the potential of this material, the form of load-carrying structures has to be designed according to the stress distribution in the structure. Partially hollow structures, such as hollow beams, or doubly curved structures, such as shells, have favorable characteristics. In hollow structures, material savings are achieved in the individual building components by locally reducing dimensions. Concrete shells, if designed properly, are able to span over large areas by transferring the loads mainly by membrane stresses. The main problem with these structures, however, is the high effort required for producing the complicated formwork. One possibility of reducing this effort is to use a pneumatic formwork. This paper describes different pneumatic formwork systems invented in the past 100 years and presents the latest developments in this area. The many types of possible applications are divided into three categories in order to obtain a clearer overview. Finally, a new construction method, called "Pneumatic Forming of Hardened Concrete (PFHC)," is presented. This method was invented at the TU Vienna and uses the pneumatic formwork in a novel way.
\end{abstract}

\section{Introduction}

The building industry consumes $50-60 \%$ of all used natural resources [1]. The largest part of these resources used by the building industry (about 40\%) goes into making concrete. In Austria, about 36 million tons of concrete is produced per year, in Germany up to 261 million tons, and worldwide up to 31,654 million tons (values based on cement consumption [2-4], assuming an average value of $12 \%$ cement per $\mathrm{m}^{3}$ of concrete [5]). Considering the raw materials used for concrete production (cement, aggregates, etc.), the transport and production of one $\mathrm{m}^{3}$ of concrete cause about $190-335 \mathrm{~kg}$ $\mathrm{CO}_{2}$ equivalents. The emissions of one $\mathrm{m}^{3}$ of concrete of class C30/37 correspond to those produced by a $2000 \mathrm{~km}$ long car ride in a convenient middle-class car, which emits $120 \mathrm{~g}$ of carbon dioxide per $\mathrm{km}$. In total, the concrete industry is responsible for a large part of the global emissions, and the worldwide concrete consumption is increasing sharply (+27\% from 2010 to 2015). Thus, it is crucial to reduce these emissions caused by the concrete industry. Concrete has a high compressive strength and a low tensile strength.
Unfortunately, most of the concrete structures do not use these properties to their advantage. In most of the structures, high tensile stresses caused by bending moments, shear forces, and torsional moments lead to low utilization of the material and require a big amount of additional reinforcement. In comparison, hollow structures or doubly curved structures such as shells exhibit advantageous loadbearing behavior if designed correctly. This leads to high utilization of the material and reduces the amount of required reinforcement.

Nevertheless, only few of these types of structures are built at the moment. The main reason is that both the complicated production and formwork as well as the falsework are very material and labor-intensive. One possibility of significantly reducing the effort required for the complicated formwork and falsework is to use a pneumatic formwork. A thin membrane is filled with air and serves as the supporting structure. Many of the existing pneumatic formwork systems struggle with process-related inaccuracies with respect to the reference geometry and the thickness of the final structure. In addition, the membrane serving as the supporting structure 


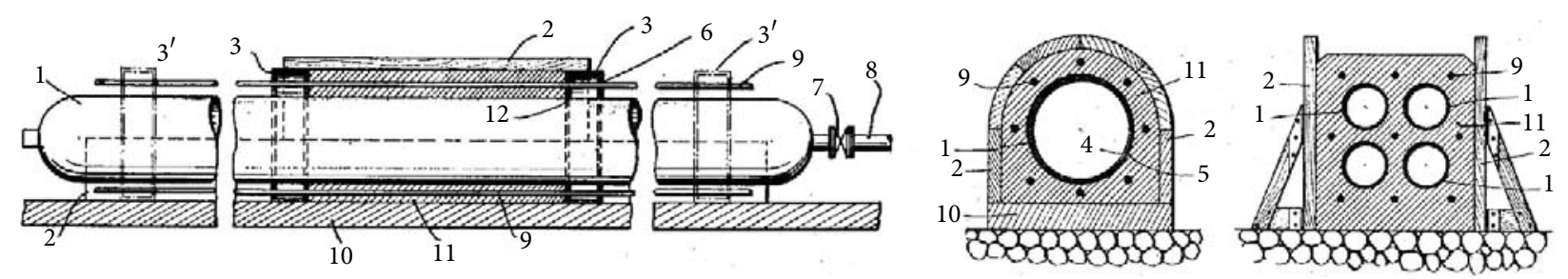

Figure 1: Construction method for pipes proposed by Nose [6].

can become deformed, particularly when a material with a comparatively high density (e.g., concrete) is applied. This results in deviations from the designed structure. To address these problems, a new construction method using pneumatic formwork in a novel way is developed in this paper.

\section{Historical Overview of Pneumatic Formwork Systems}

There is a wide range of different pneumatic formwork systems. The following comprehensive overview shows different fields of application and different approaches. Existing problems of the various systems will be analyzed, and the results will serve as the basis for using the existing systems in novel ways and for the development of new systems.

One of the first applications of pneumatic formwork was patented in 1926 [6] and 1931 [22] by Nose for the production of culverts and concrete pipes. As shown in Figure 1, he used tube-like inflatable structures, mounted them on outer frames (e.g., wooden sideboards), and filled the remaining space with concrete. Afterwards he deflated and removed the membrane.

A few years later, in 1941, Neff was the first to invent a technology for building cost-efficient houses using pneumatic formwork $[7,23]$. In this method, a membrane with the desired form is produced first. This membrane is tied down with ropes at the edges and the bottom to prevent it from lifting off the ground. In the next step the reinforcement is mounted and the concrete is sprayed onto the membrane in multiple layers until the required thickness is obtained. Subsequently, the membrane is deflated and removed. Finally, the windows and the door are cut out. Figure 2 shows a concept drawing of the construction method and Figure 3 shows a concept drawing of an improved version. Neff had the problem that the tensile forces at the circumference led to cracks in the lower parts of his shells. He improved his construction method in 1952 by adding wrappings in the lower part of the structure to absorb the tensile forces, as shown in Figure 3. He graduated the length of the wrappings in the transition area from a cylindrical to a spherical form [8].

In 1949, Mathews patented a method for the production of hollow concrete units [9]. An inflatable core positioned between a bottom and top plate made of steel is used to leave the desired space in between the plates, as shown in Figure 4. The main purpose of this was to reduce the required concrete mass as well as the weight of the elements.

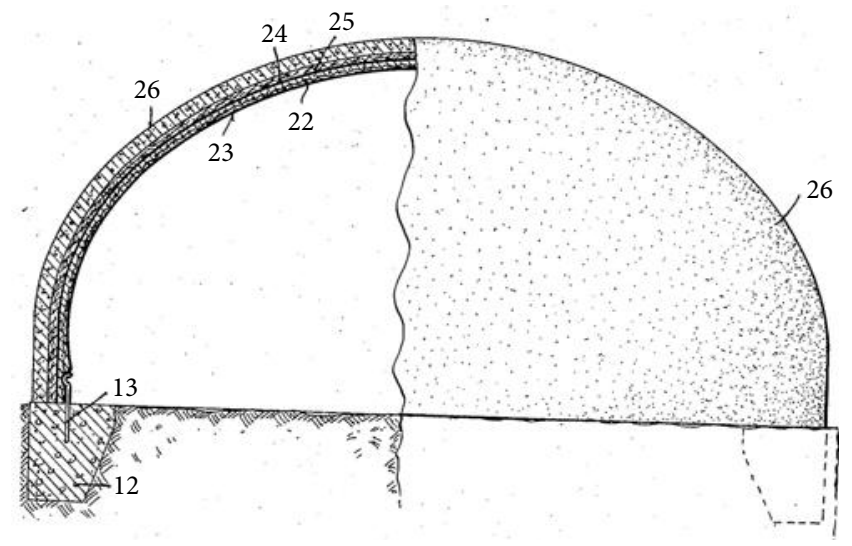

FIGURE 2: Concept drawing by Neff for the construction of concrete shells [7].

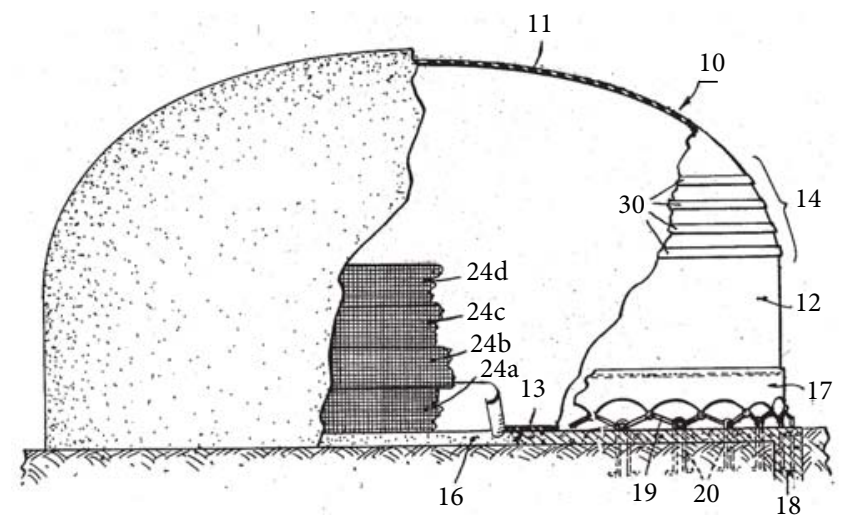

FIgURE 3: Concept drawing of Neff's "improved method of erecting shell form concrete structures” [8].

Leonhardt also worked with a type of pneumatic formwork. He used tubular inflated rubber hoses as cladding tubes. He placed additional steel rings at the bends of the hoses and then inflated the tubes. By doing this, a ribbed internal surface of the channel was achieved with the purpose of reducing the friction of the prestressing cables [10]. Figure 5 shows a drawing of the production principle.

In 1968, Mora patented another method for the construction of lightweight wall elements [24]. Elliptical inflatable tubes are placed between facing skins made of a suitable 


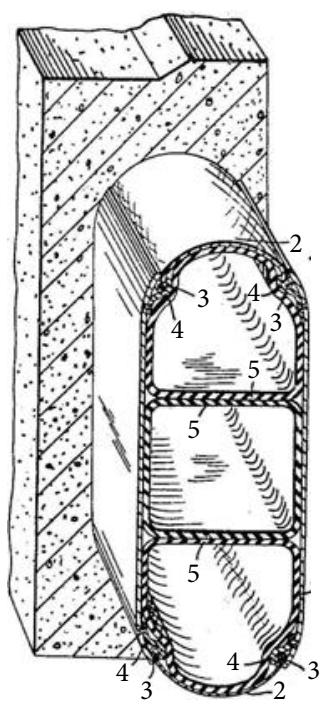

FIgURE 4: Construction method for hollow lightweight wall elements, invented by Mathews [9].

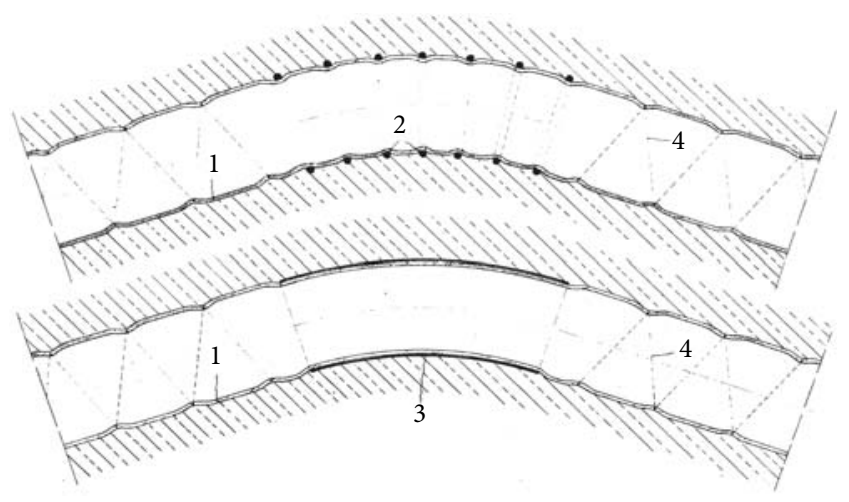

FIGURE 5: Concept drawing by Leonhardt for using inflated tubes as ribbed rubber hoses [10].

material (e.g., plastic, textile, rubber, fiberglass, or combinations thereof). Unlike Mathews he rotated the pneumatic structures by $90^{\circ}$ and installed them vertically in the wall elements. After inflation of the formwork, the concrete is cast in the hollow space between the tubes and the skin. It is crucial to fix the tubes securely in their position to avoid lift-off due to the pressure exerted by the concrete.

Bini invented an alternative construction method for shell houses in 1969, which is described in [11, 25-27]. As opposed to all the methods described above, he cast a flat concrete plate and then formed the green concrete into a doubly curved shell. He fixed the membrane inside a groove as shown in Figure 6(a) running in the circumferential direction by inflating an additional pneumatic tube inside of it. The membrane, serving as formwork, is folded so as to accommodate the strains in the circumferential direction during inflation by unfolding. In the next step, the reinforcement is mounted. In order to absorb the strains in the peripheral reinforcement, the bars are formed into springs as shown in Figure 6(b). A straight reinforcement bar is fixed in the middle of the spring and pulled out slowly during the transformation process from the flat plate to the doubly curved shell. Due to the larger strains in the area in between the edges and the plate center occurring during the transformation process, the thickness of the flat green concrete plate increases from the edge to that area and decreases again to the center of the plate as shown in the concept drawing in Figure 7. After finishing the transformation process, the concrete is compacted by surface vibrators pulled by ropes. Bini built over 500 shells with this construction method. An exemplary list of binishells built in Australia can be found in [28]. In 1975, a modified version of this method was used by the US Army. The main difference was that they used steel-fiber reinforcement instead of the complicated spring reinforcement and a membrane with a greater thickness of up to $3.2 \mathrm{~mm}$. Various problems occurred during the production of the shells. The strains in the green concrete during the transformation process led to variable shell thickness across the structures. In addition, it is generally not possible to provide the same properties of fresh concrete over the whole plate for a longer period of time. Consequently, geometric deviations occurred, which led to the collapse of some of the shells built with this method. Due to these problems, this construction method slowly disappeared from the market.

In 1969, another construction method for the production of cost-efficient houses was patented by Heifetz in Israel. Similarly to Neff's method, a pneumatic formwork is inflated, reinforcement is mounted on the outside of the membrane, and shotcrete is applied $[12,29]$. The difference is that Neff used a pressure of $0.5-2.0 \mathrm{kN} / \mathrm{m}^{2}$ in the pneumatic formwork and Heifetz used a higher pressure $\left(4.0-10.0 \mathrm{kN} / \mathrm{m}^{2}\right)$ in order to minimize the deformations during concrete spraying. The different production steps are shown in Figure 8.

In 1971, MacCracken patented a method for building selfsupporting shell roofs made of a flexible, heatable plastic material [13]. As shown in Figure 9 flexible structure is inflated and supported by the air pressure. The structure is hardened by applying heat with hot gases or by feeding hot fluids through ducts to achieve a heat exchange with the roof. The ducts can later be used to melt any snow accumulated on the finished structure.

Isler also experimented with pneumatic formworks. He applied different materials such as concrete, gypsum, clay, and water which he froze afterwards, onto the pneumatic formwork [14]. He also used the inflated membranes shown in Figure 10(a) for the form-finding process for humpback shells. Figure 10 shows an urban project from 1977, in which a balloon served as pneumatic formwork to build earthquakeresistant houses in Iran [30]. Locally available materials such as sand and clay were to be applied to the formwork. Unfortunately the project was canceled due to the political situation in the country. Preliminary experiments were performed in Burgdorf in Switzerland with a gypsum-clay as well as a gypsum-cement mix. The application process is shown in Figure 10(b). The balloon had a two-chamber system to allow a deviation from the spherical shell form and to avoid the need for additional fixations at the circumference of the pneumatic structure. The manufactured prototype slowly 


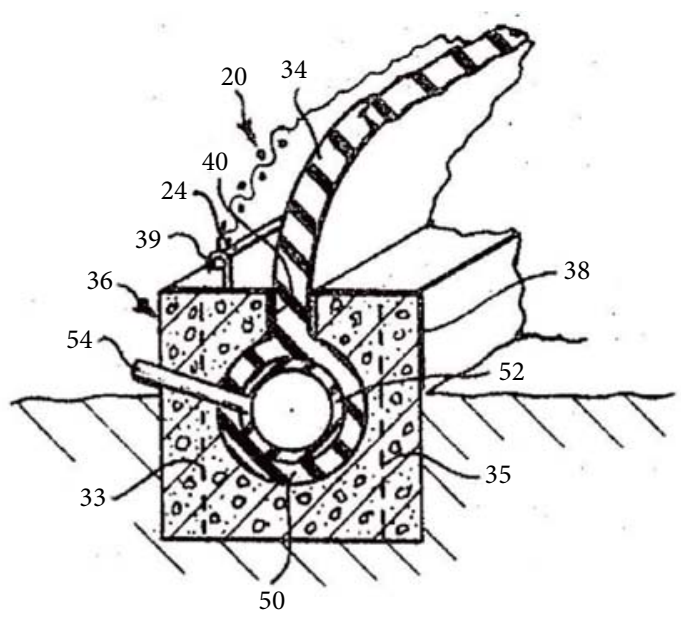

(a)

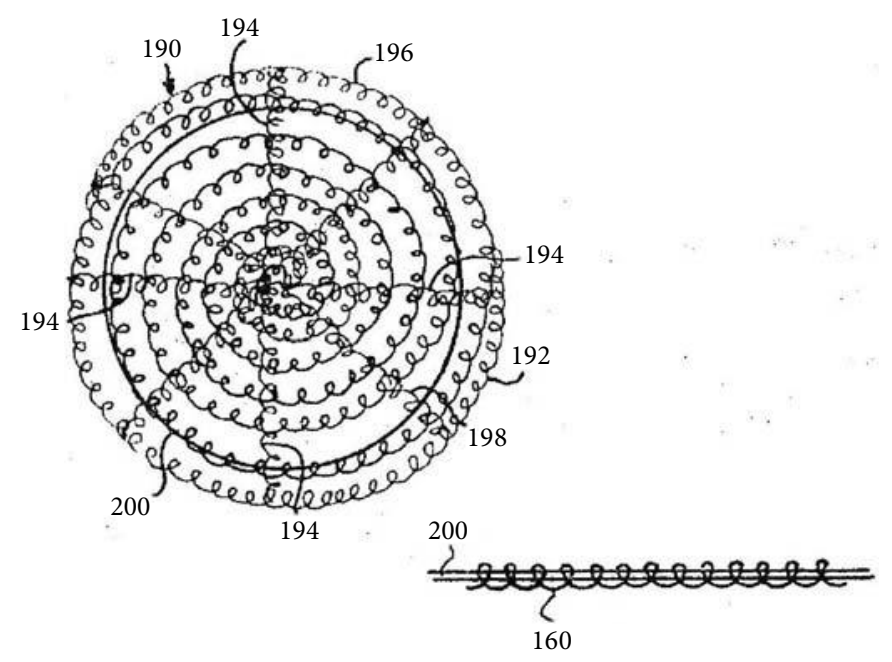

(b)

Figure 6: Bini's fixation of the membrane in the groove (a) and the special perpendicular reinforcement (b) [11].
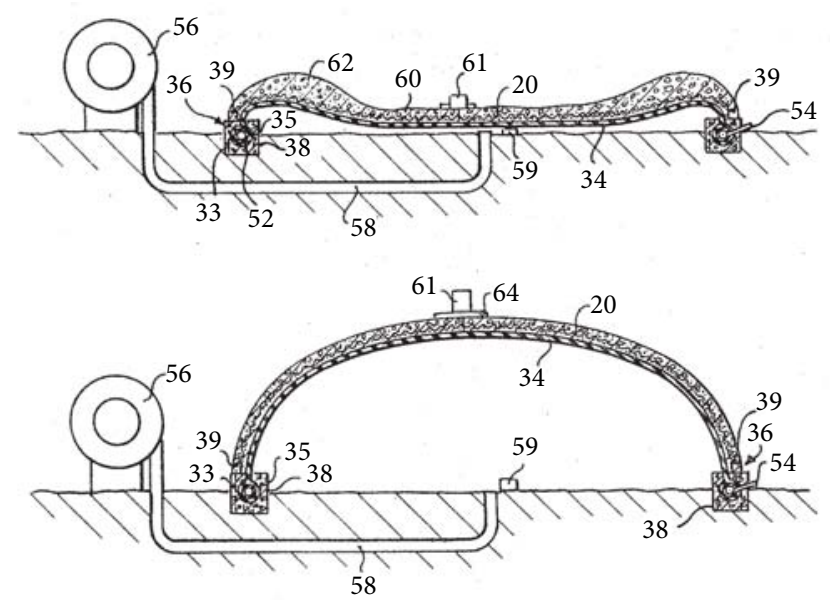

Figure 7: Bini’s shell construction method [11].

failed due to buckling as a result of the low freeze-thaw resistance of the materials. A gypsum-clay mix can only resist a dry cold, as would be found in Iran.

In 1978, Prouvost invented a pneumatic formwork method for houses or similar buildings that is close to previously developed methods. It is described in [15]. As opposed to the previously invented methods, he used a two-chamber system, which avoids the need for elaborate anchoring of the pneumatic formwork at the bottom, as shown in Figure 11.

A further construction method for the production of concrete domes was invented in 1979 by South. Like others before him, he also sprayed concrete onto an inflated pneumatic formwork, as described in [31, 32]. In contrast to Neff and Heifetz, South mounted the reinforcement onto the inside of the membrane and improved the stiffness of the inflated membrane by applying an additional layer of polyurethane before the reinforcement and the concrete were applied. This layer also serves as insulation.

Nicholls patented a shell construction method in 1984, in which he applied a dry concrete premix onto a weakly curved pneumatic formwork. Afterwards, the plate was transformed into a doubly curved shell with the aid of the pneumatic formwork [33]. Finally, water was sprayed onto the shell to set the hardening process in motion. Two properties limit the application of this construction method. First, the thickness of the concrete premix can easily change during the transformation process, resulting in a variable thickness of the shell. Secondly, the water-cement ratio varies significantly across the finished shell due to the application of the water spray. Thus, poor and varying hardened concrete characteristics have to be expected.

Schlaich and Bergermann came up with the idea of using additional ropes to influence the form of the pneumatic formwork. As described in [34], these ropes create something akin to ribs and have a beneficial effect on the load-carrying behavior of the shell. Another idea of Schlaich consists in placing precast concrete parts on a pneumatic formwork to induce the desired deformations during assembly and subsequently filling the gaps with cast in situ concrete [35]. This makes it possible to adjust the air pressure in the pneumatic formwork during construction, before the individual elements are connected.

An extension of the construction methods invented by Neff and Heifetz was developed by Thoeny in 2005 [16]. The basic principle, shown in Figure 12, consists in using one or more pneumatic structures, draping fabric over the said structure(s), and applying a coating (e.g., sprayed concrete). Subsequently the pneumatic formwork can be deflated and removed.

Pneumatic formwork can also be used to build structures out of ice. Exemplary Kokawa builds ice shells using inflated formworks for about 30 years. He influences the shape of 

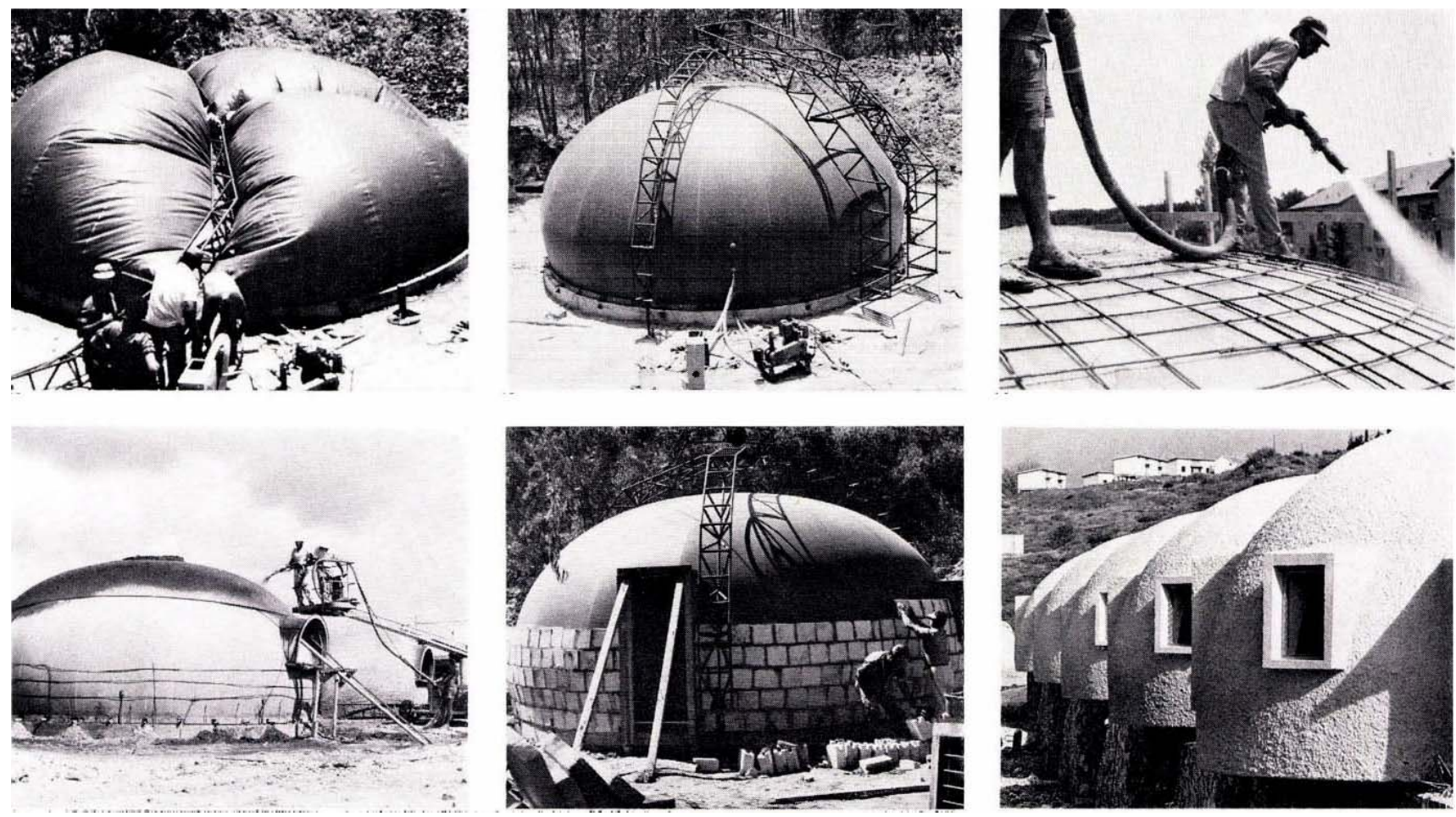

Figure 8: Domecrete construction method invented by Heifetz [12].

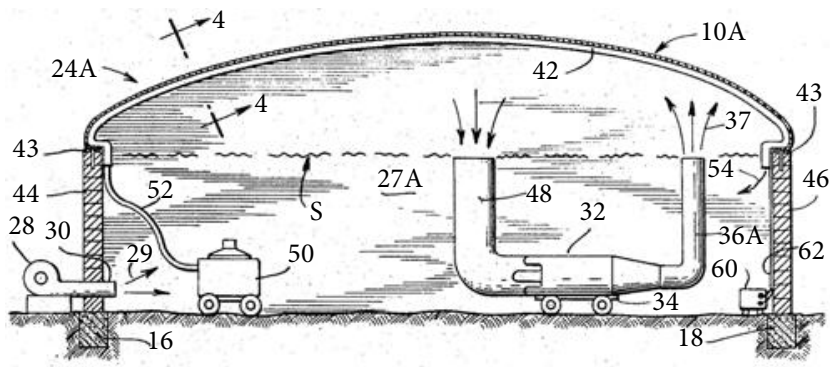

Figure 9: Method developed by MacCracken for building reinforced plastic shells by inflating the formwork and hardening the shell by heating [13].

the pneumatic formwork and subsequently the shape of ice shell by prestressing additional ropes against the membrane as described in [36]. After inflation of the membrane water is sprayed onto pneumatic formwork until the required material thickness is reached.

An improved method to build structures out of ice using a flexible mould is currently used by Pronk. Like Kokawa he uses an inflated membrane with additional ropes as formwork. The water is replaced by reinforced ice, a mixture of water and sawdust called Pykrete, and is sprayed on the pneumatic formwork using a centrifugal pump. So far he built a number of impressive structures such as a $30^{\circ} \mathrm{m}$-span ice dome or an ice church called the Sagrada Familia in Ice as described $[17,18]$ and shown in Figure 13.
Another idea is presented by Verwimp et al. in [37]. A thin textile-reinforced concrete (TRC) layer in its unhardened state is applied onto a flexible formwork (e.g., a pneumatic formwork) to increase the stiffness of the membrane. After the first layer has hardened, an additional concrete layer can be applied, which causes only minor deformations of the thin concrete shell. The textile reinforcement in the TRC layer also serves as part of the statically required reinforcement and (partly) replaces the conventional reinforcement.

Quinn and Gengnagel describe in [38] the use of pneumatic formwork for the erection of elastic grid shells, highlighting speed, safety, control, and costs. The pneumatic formwork is inflated and lifts the gridshell until the required shape is reached. The system was already tested within a small prototype within a student workshop.

A different application of pneumatic formwork was first tested in 2014 by a team of the University of Stuttgart [19]. Developed following the biological investigation of the water spider, a membrane was inflated and subsequently reinforced with epoxy-resin-impregnated carbon fibers. A six-axis robot was placed in the middle of the structure and sequentially applied the preimpregnated fiber roving onto the inside of the surface where statically required [39]. Figure 14 shows the construction principle. After the carbon fibers had been applied and the impregnation had hardened, the membrane could be deflated and the openings cut out. The impregnated fibers serve as the supporting structure and the membrane serves as a leak-proof protective cover. The demonstration structure with a span of $8.5 \mathrm{~m}$ erected in Stuttgart covers an area of $40 \mathrm{~m}^{2}$ and encloses a volume of 


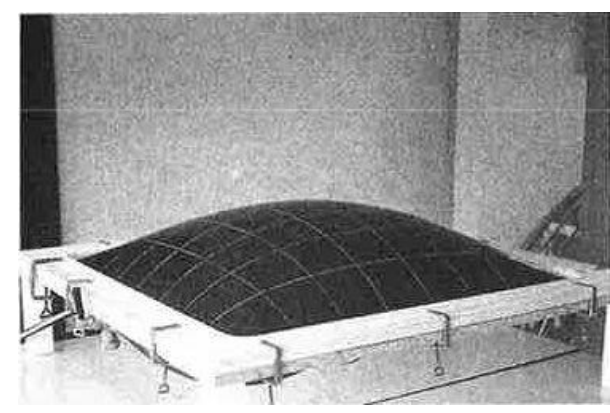

(a)

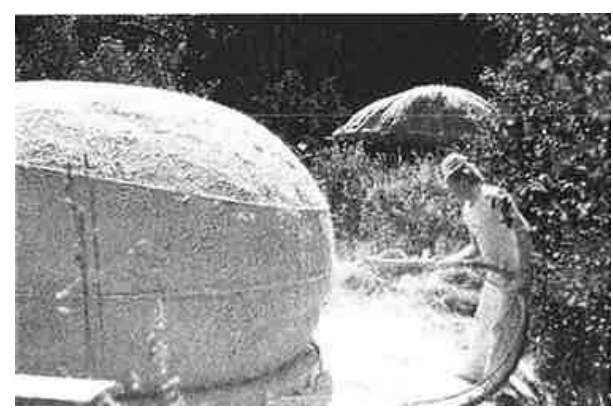

(b)

FIGURE 10: Form-finding with pneumatic formwork (a) and production of a prototype of a circular house with a gypsum-clay mix (b) by Isler [14].

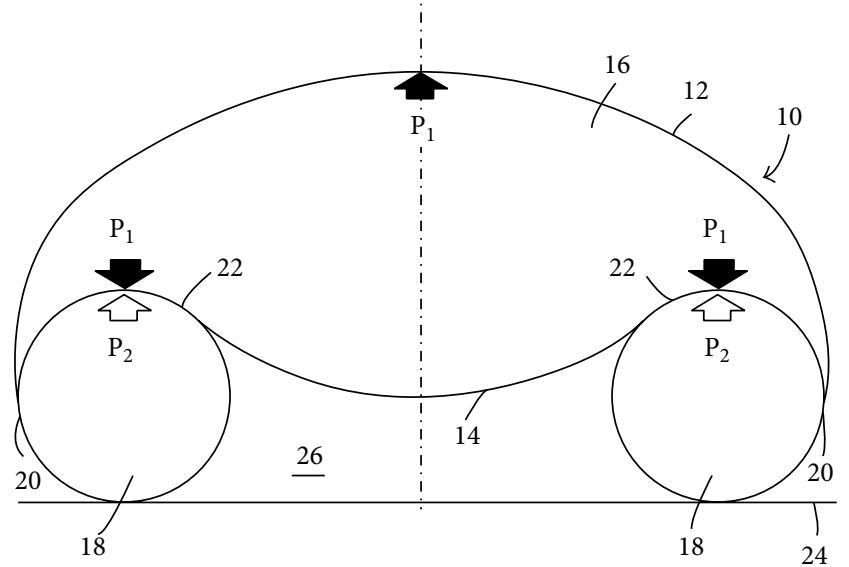

FIGURE 11: Construction method invented by Prouvost with two air chambers to avoid the need for fixations at the circumference [15].
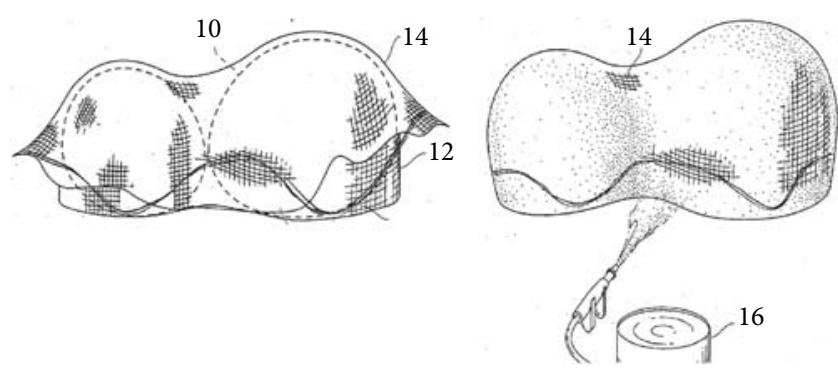

FIGURE 12: Shell construction method proposed by Thoeny using an additional fabric layer before applying shotcrete [16].

$125 \mathrm{~m}^{3}$. The total weight of the prototype shell is only about $260 \mathrm{~kg}$. Figure 15 shows the finished prototype.

Nowadays, pneumatic formwork systems are used frequently, mainly employing the systems developed by Nose, Heifetz, and South. Leading companies are SO.CA.P. Srl, Dome Technology, Monolithic, Pirs, YSM, and Concrete Canvas [20, 21, 40-43]. The construction principle of Monolithic is shown in Figure 16 using the system of South. Concrete Canvas uses fabric panels impregnated with a dry concrete premix and connects them in a prefabrication process in order to complete the structures. This allows for easy delivery of the construction material to the building site. This construction method is suitable for small shelters with low static requirements. They can easily be assembled by first inflating the formwork and then spraying the water. As with the system developed by Nicholls, a varying water-cement ratio across the structure has to be expected.

\section{Classification of Existing Pneumatic Formwork Systems}

Analyzing the existing systems, the formwork systems are classified into three main groups which are subdivided into four subgroups, as shown in Figure 17. The first main group represents the systems that use the pneumatic formwork as an internal spacer to build tubes or hollow elements. This group is called "air space pneumatic formworks" and includes, for example, the systems proposed by Nose, Mathews, Loenhardt, or Mora. The second main group is called "classical pneumatic formworks." It contains the systems in which a membrane is inflated first and the concrete or another material is applied afterwards, such as the systems developed by Neff, Heifetz, Prouvost, South, Schlaich and Bergermann, Thoeny, Verwimp et al., or Doerstelmann et al. The third main group, called "lifting pneumatic formworks," encompasses the systems in which the concrete or a cement matrix is applied onto a flat plate, which is subsequently transformed into a doubly curved shell. Examples are the systems invented by Bini or Nicholls.

3.1. Air Space Pneumatic Formworks. Air space pneumatic formworks are the oldest known types of inflatable formworks. They are used for two different purposes: either to form a hollow space within a structure for a special purpose (e.g., a pipe) or to form an air space in areas of low stress within a solid building component to save construction material. Particular attention has to be paid to fixing the pneumatic structures in the right position and to preventing them from lifting off. If the entire pneumatic structure is fully enveloped by concrete, it has to be taken into account that the membrane remains embedded in the finished structure. 

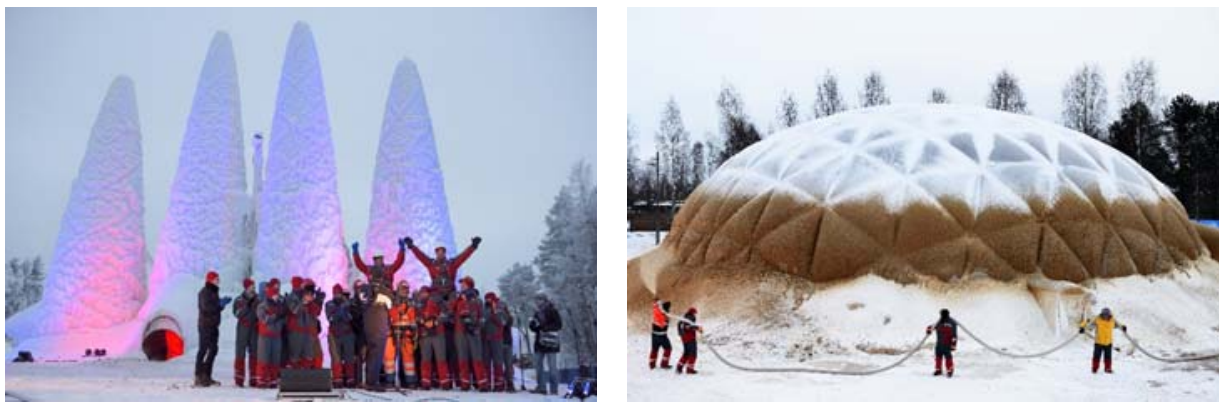

FIGURE 13: Ice structures built with pneumatic formwork by Pronk [17, 18].
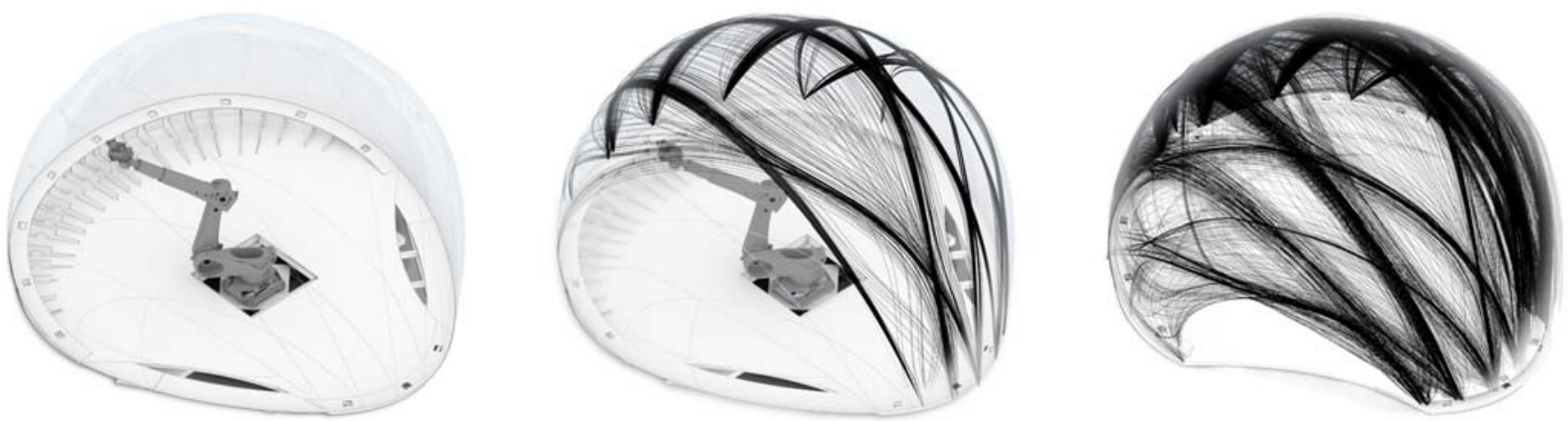

FIGURE 14: Construction method used for the ICD/ITKE research pavilion in 2014/15 ${ }^{\odot}$ ICD/ITKE University of Stuttgart.

If the formwork is used to create some kind of tube, the membrane can be deflated, removed, and reused. The most frequent application of pneumatic formwork in concrete construction is in light wall elements or light slab systems. It has to be taken into account that additional formwork or a trench is required to shape the external surfaces of the structure.

3.2. Classical Pneumatic Formworks. Classic pneumatic formworks are suitable for building thin shell structures. Here, the pneumatic formwork is used to actively shape the structure. This means that the pneumatic formwork has the form of the finished structure. If a one-chamber system is used, the air pressure is the same at any point and acts perpendicular to the membrane. Since the pressure is constant over the entire surface, a pneumatic structure tends to have a spherical shape. The shape can be influenced by using a knitted or glued pneumatic structure made of tailor-made membrane strips or by prestressing the membrane with wrappings or ropes. However, the tensile force in the membrane is always directly dependent on the internal pressure of the pneumatic formwork and the radius of curvature. Pneumatic structures generally have small radii of curvature and do not have to resist large loads. Additionally, large deformations are permitted in most cases. Consequently, most differences in curvature have no effect on usability. In contrast, in pneumatic formworks used for concrete structures, the pressure exerted by the concrete is high in comparison to the internal pressure and additionally the radius of curvature is relatively large. Sobek [35] analyzed green concrete and found that it is sensitive to deformations. He investigated the influence of deformations on different mixtures and their hardening characteristics. The adverse influence of deformations on the concrete properties can be improved by using a tailored concrete mixture. Large deformations and the long time required to apply the concrete over the entire pneumatic formwork still remain as central problems. A deviation from the desired rotationally symmetric shell form leads to varying radii of curvature and differing stresses in the membrane. The result is varying deformations during the application of the concrete on the membrane. However, this is not a problem as long as the shell size is small and the utilization factor of the concrete is low.

To use classic pneumatic formworks, several boundary conditions have to be fulfilled. Sobek described the design, the construction principle, and the production of classic pneumatic formworks in [44]. He paid special attention to the stresses in the concrete shells before and after deflation of the pneumatic formwork (internal pressure and dead weight, resp.) and found that pneumatically formed concrete shells do not always exhibit membrane stress, as opposed to what was thought previously. It is rather in the hand of the designer to create a shell shape suitable for construction with pneumatic formwork. Sobek also suggested that a big variety of different 

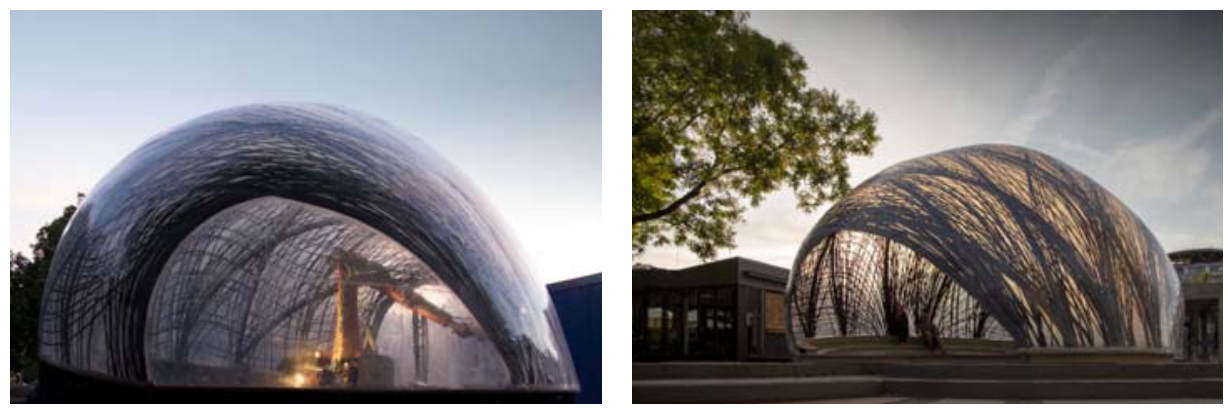

FIGURE 15: Inflated pavilion strengthened with carbon fibers which are applied by a robot arm $[19]{ }^{\odot}$ ICD/ITKE University of Stuttgart.

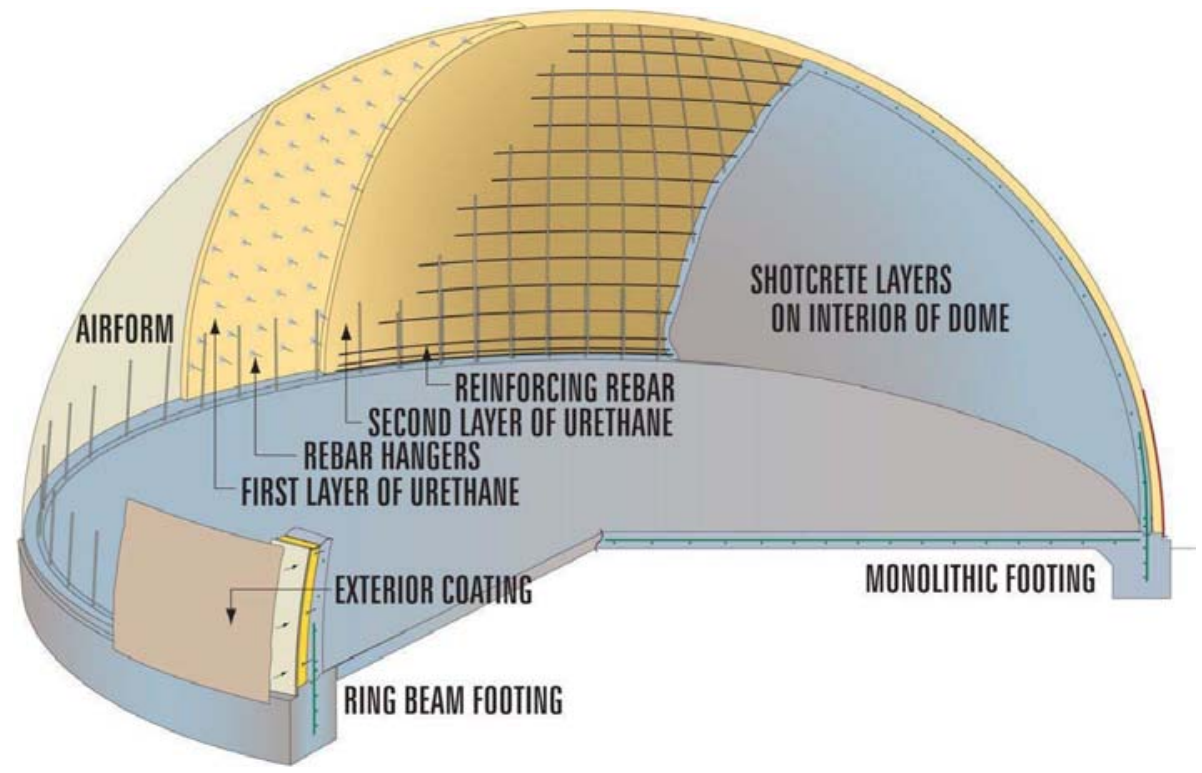

FIGURE 16: Schematic drawing of the construction method used by Monolithic ${ }^{\circledR}$ Monolithic [20].

shapes can be built with classic pneumatic formworks if the pressure is controlled very precisely. It has to be taken into account that the atmospheric pressure $\left(1-2 \mathrm{kN} / \mathrm{m}^{2}\right)$ and the change of temperature (change of the air volume) have a great influence on the shape of the pneumatic formwork. In [45], van Hennik and Houtman analyzed the behavior of irregular classic pneumatic formworks. They stated that it is possible to deviate from the spherical form, but this results in local deformations of the membrane. In addition, unfavorable tensile stresses occur in the finished structures, which limit their potential significantly.

Different modifications to improve the stiffness of the membrane for later application of concrete have been developed in the past. Experience shows that systems using an additional stiffening layer, for example, the system developed by South and used by Dome Technology, Monolithic, and Pirs to build rotationally symmetric domes, have the highest potential and can be used to build domes with spans of over $20 \mathrm{~m}$. An example of a finished concrete shell built by Dome Technology is shown in Figure 18.
3.3. Lifting Pneumatic Formworks. Inflatable structures are often used as lifting devices. They are characterized by low weight, comparatively low acquisition costs, and ease of inflation and deflation. Depending on the tensile strength of the membrane, the strength of the seams, and the performance of the pressure-producing device (e.g., a compressor, a side channel blower, or a fan), high loads can be lifted, for example, with lift pads.

Large lift pads can also be used as pneumatic formwork to produce shells. A malleable material is placed on the deflated pneumatic formwork and is transformed into the desired shape when the formwork is inflated.

If the added material is still soft during inflation, the lifting pneumatic formwork is said to be form-active (the same as classic pneumatic formworks). If the formwork deviates from the planned shape, the shape of the finished structure will deviate too. During the transformation process, the soft material has to be able to absorb the strains that occur during the transformation of the flat plate into a doubly curved shell. If, for example, concrete is used as the 


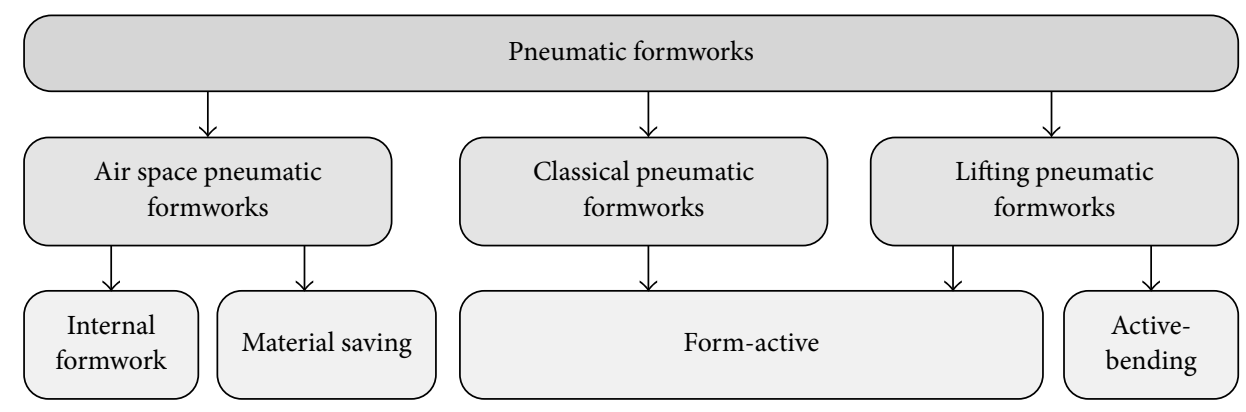

FIGURE 17: Categorization of the different pneumatic formwork systems.

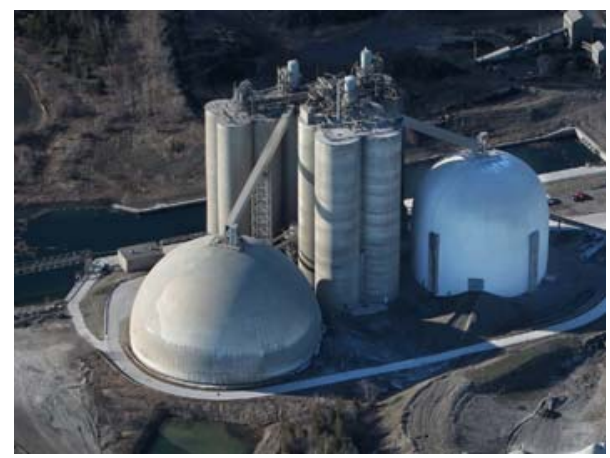

FIGURE 18: Rotationally symmetric concrete dome built by Dome Technology [21] ${ }^{\odot}$ Dome Technology.

construction material, it has to be taken into account that different flow properties (caused, e.g., by different concrete ages) across the surface can cause a deviation from the desired shape. This can be a problem because unexpectedly high stresses can occur in the finished structure. It is important that the pneumatic formwork also is able to absorb the large strains in the circumferential direction. Hence, either a membrane with very high elasticity is used or the pneumatic formwork has to be folded at the bottom which then unfolds during the erection process.

An advantage of the lifting pneumatic formworks compared to the classical pneumatic formworks is that the moulded material can easily be applied onto the initially flat membrane and transformed afterwards. Since shell structures have small thickness-to-span ratios, only very low pressure is needed for the transformation. If, for example, a concrete plate with a thickness of $100 \mathrm{~mm}$ is transformed, a pressure of only 25 mbar is sufficient for lifting.

Up to now, only green concrete, concrete premixes, or a concrete premix in combination with a coating fabric has been lifted, and they have been accompanied by geometric deviations from the planned structure. In order to take advantage of the favorable load-bearing behavior of doubly curved structures with large spans, the shell has to be built with minor deviations from the optimized geometry.

In the following part of the paper, a new and more precise construction method, called Pneumatic Forming of Hardened Concrete (PFHC), is presented, which uses a lifting pneumatic formwork in a novel way.

\section{The Pneumatic Forming of Hardened Concrete Construction Method}

The PFHC construction method was derived from hydroforming, as known from mechanical engineering, and represents a new way to build doubly curved shells in an economical as well as labor and resource-efficient manner. As described in [46], a flat, hardened concrete plate is transformed into a doubly curved shell with the aid of pneumatic formwork and post-tensioning tendons. During the transformation process, the plate is lifted and distorted by inflating the pneumatic lifting formwork and stressing the post-tensioning tendons as shown in Figure 19.

Erecting a shell from a flat plate causes large strains in the circumferential direction. To absorb these strains, wedge-shaped gaps have to be left in the flat concrete plate using tailored formwork. Pneumatic formwork with almost the same diameter as the concrete shell is used to lift the concrete plate to transform it into a shell. Additional pneumatic wedges are fixed between the concrete elements to protect the balloon in the areas of the wedge-shaped gaps during the erection process. Using a reinforcement with linear-elastic material behavior, a low modulus of elasticity $\left(50,000-100,000 \mathrm{~N} / \mathrm{mm}^{2}\right)$, and high breaking strength $(>2 \%)$, for example, steel ropes or glass-fiber-reinforced plastic rods, ensures that large strains in the concrete members can be accommodated. As explained in [47], this novel building method could be used for a large number of different doubly curved surfaces. Because hardened concrete cannot expand or contract much, large concrete plates can only be bent in one direction, assuming that the used type of concrete and the reinforcement are able to absorb the occurring strains. Hence, developable surfaces have to be used. The challenge for the design of these surfaces is to produce nonoverlapping representations consisting of developable singly curved strips.

4.1. Active-Bending Lifting Pneumatic Formwork. Using PFHC changes the application of the pneumatic formwork from form-active to bending-active. The form of the pneumatic formwork has no influence on the final form of the shell. The pneumatic formwork only serves as a kind of sealing layer. Thus, if the flat plate is produced with high precision and all wedge-shaped gaps are closed during the 

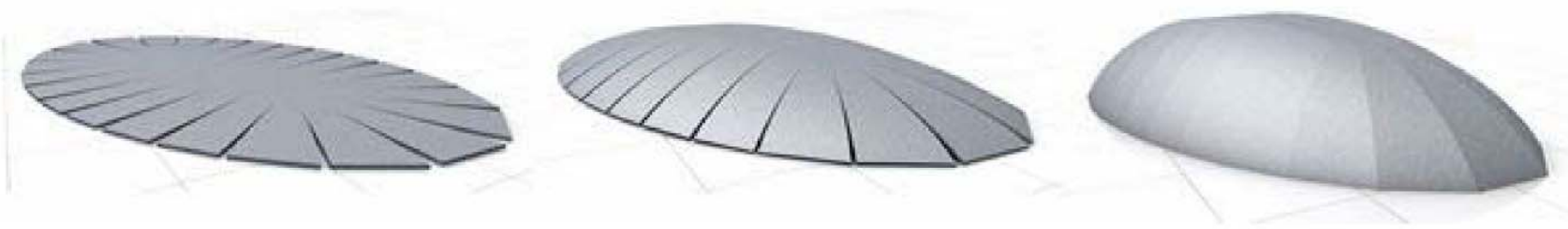

FIgURE 19: Pneumatic Forming of Hardened Concrete (PFHC) construction method.
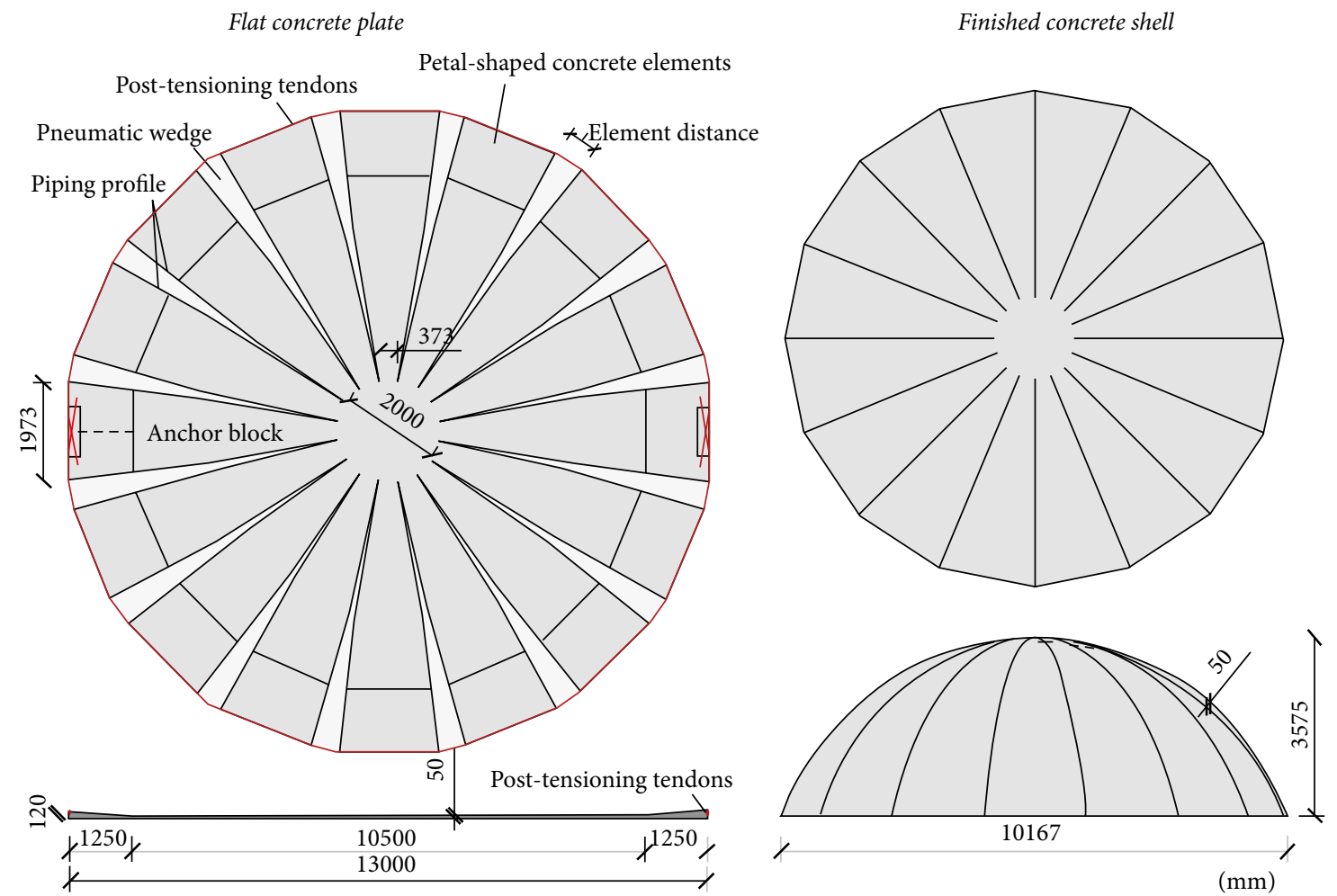

Figure 20: Dimensions for the erection of a spherical shell (large-scale experiment).

transformation process, the resulting final structure can be built with only minor deviations from the geometrically optimal shape. The final form is found automatically as the wedge-shaped gaps close. Therefore, large rotationally asymmetric forms with positive Gaussian curvature can be realized.

4.2. Concrete Properties. First, the flat plate is cast using conventional concrete. Then, the hardened plate is transformed into a doubly curved shell. This allows using proven manufacturing techniques and ensures a high quality of the concrete, as well as precise dimensions of the plate. As explained in [48], the results of a large number of tensile and bending tests on specimens with different concrete properties and different concrete ages showed the following: the reinforcement has a high impact and the concrete parameters have a very low impact at the bending properties of the concrete plates. The single but very important requirement is for the concrete properties not to vary across the concrete plate.

4.3. Practical Applicability. In November 2012, a first prototype of a concrete shell with a $13 \mathrm{~m}$ span was built in Amstetten, Austria, to test the feasibility of the construction method [46]. The concrete shell with a height of $3.29 \mathrm{~m}$ and a diameter of $10.81 \mathrm{~m}$ was erected from a flat plate with a thickness of $50 \mathrm{~mm}$ and a diameter of $13 \mathrm{~m}$. Figure 20 shows the initially flat plate and the finished concrete shell. The production of the $13 \mathrm{~m}$ concrete shell was carried out in different production steps.

In the very first step it was necessary to create a flat working space for the subsequent production steps. Then, two layers of thin foil $(110 \mu \mathrm{m})$ with a fleece as an interlayer, serving as a lifting formwork, were placed on the flat working space. The pneumatic wedges, used to reduce the stresses in 

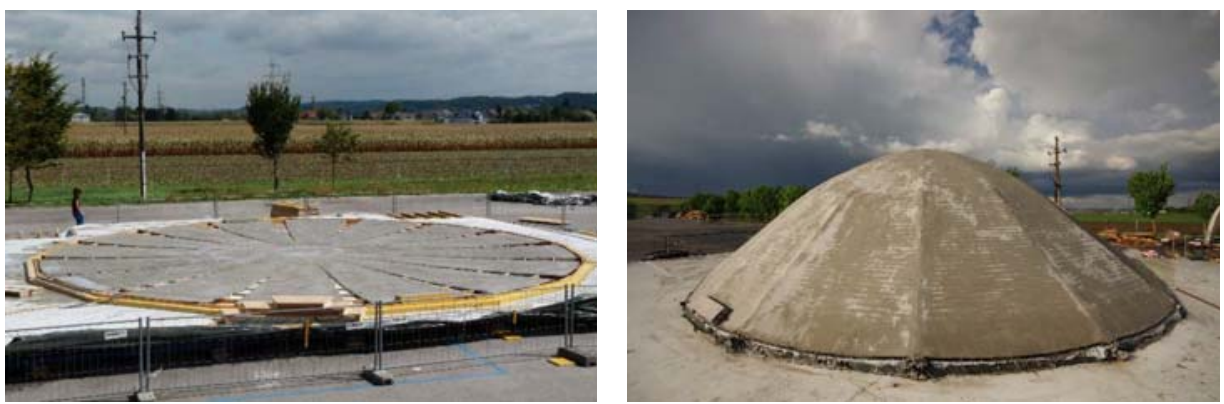

FIGURE 21: Large-scale experiment in Austria: erection of a spherical shell using PFHC (2012).

Flat concrete plate

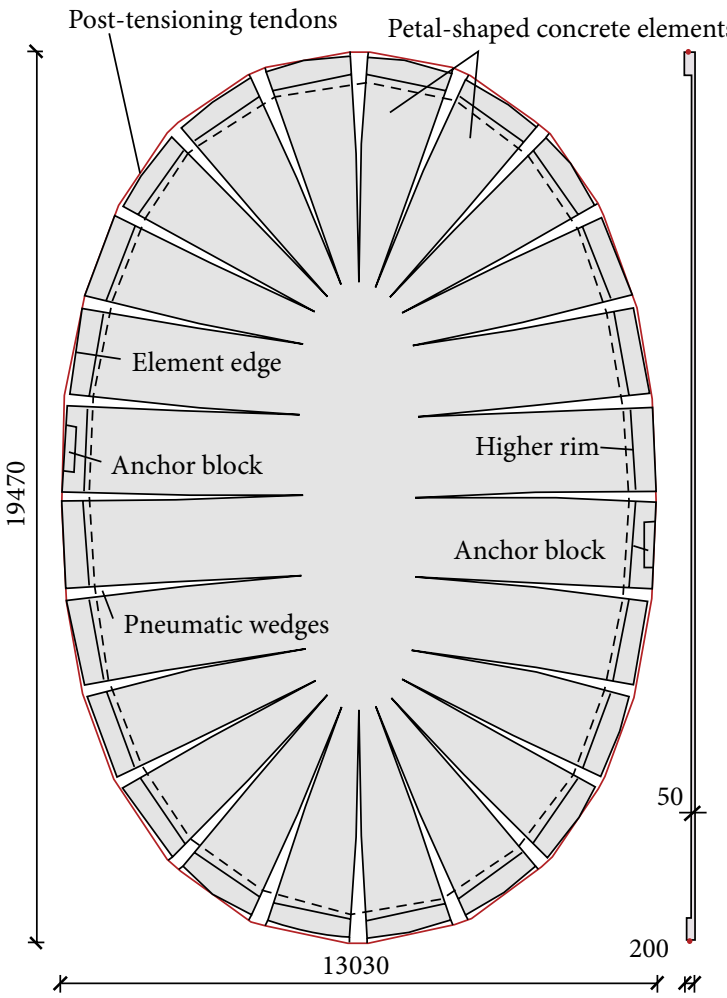

Finished free-form shell
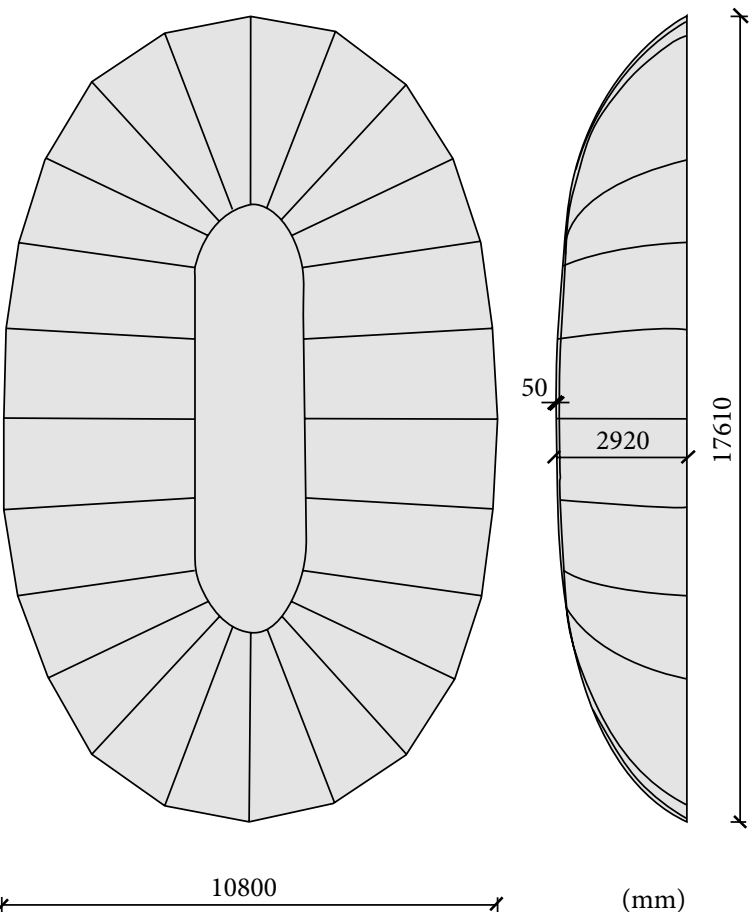

$(\mathrm{mm})$

FIGURE 22: Dimensions for the erection of a free-form shell (large-scale experiment).

the foil during the transformation process, were placed onto the two layers of foil before the formwork for the wedges was mounted. $1200 \mathrm{~m}$ of steel rope (diameter $5 \mathrm{~mm}$ ), used as radial reinforcement, was fixed between a steel ring in the middle of the plate and the outside of the formwork ring. The next production step was to fix conventional reinforcing steel rods (6 mm diameter), serving as constructive reinforcement, onto the steel ropes in the tangential direction. In the last step the concrete was cast into the formwork. After three months of hardening, the flat concrete plate was transformed into the finished shell structure within 8 hours by the following process.

First, the pneumatic wedges were inflated with the aid of a compressor. Then, the foil serving as a pneumatic formwork was inflated and thus lifted the entire construction. Additionally, post-tensioning tendons, mounted at the slab edge, were tightened with four hydraulic jacks. Subsequently, the post-tensioning tendons were fixed in place. Finally, the joints between the elements were filled with a mineral filler. Figure 21 shows the flat concrete plate and the transformed shell structure in its final state.

In spring 2014, a second prototype of a free-form shell spanning $17.6 \times 10.8 \mathrm{~m}$ and with a height of $2.9 \mathrm{~m}$ was built in Vienna, Austria, to test the feasibility of the new building method for free-form shells (Figure 22) [48].

The use of the peripheral areas of shell structures is difficult, owing to the small height of the structure in those areas. It can be challenging, for example, to fit furniture in 

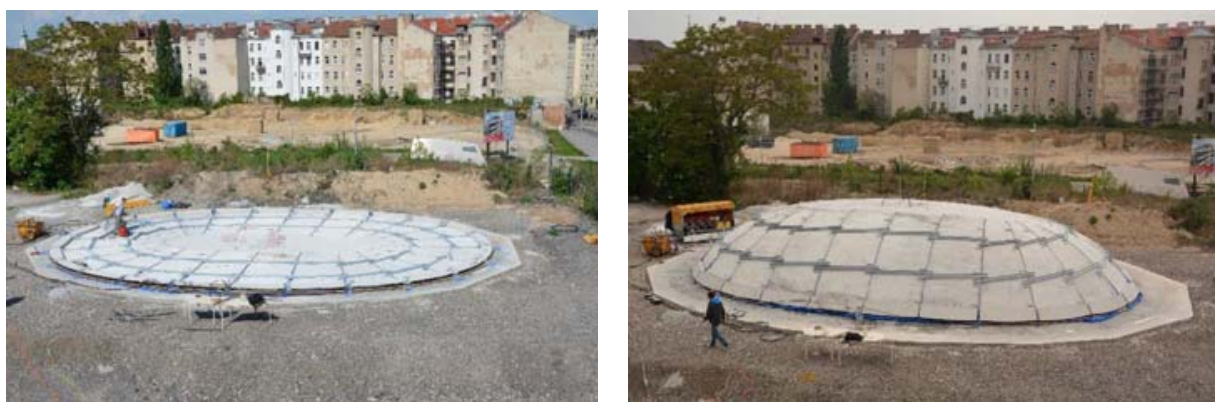

FIgURE 23: Large-scale experiment in Austria: erection of a free-form concrete shell using PFHC (2014).

these spots. The shape of an ellipsoid was therefore modified and used to create a similar structure with a different curvature, so as to obtain a larger floor area with adequate room height.

The "perfect" smooth geometry was discretized into a polyhedron and split into 24 segments to allow the use of the PFHC method. Subsequently, a polyhedral flat plate was produced, which consisted of the previously mentioned 24 segments and 24 wedge-shaped gaps used for compensating the compressive strains in the circumferential direction during the transformation process from the flat plate to the free-form shell.

The thickness of the initially flat plate was $50 \mathrm{~mm}$, except for a $0.5 \mathrm{~m}$ wide strip at the outer edges of the 24 segments, where it was $200 \mathrm{~mm}$. The larger thickness at the edge of the plate served as ballast and was necessary to allow for the distortion of the concrete plate. Otherwise, the plate would be lifted as a whole by the pneumatic formwork. Stainless steel ropes with a $5 \mathrm{~mm}$ diameter and $7 \times 19$ wires were selected as reinforcement. Conventional $6 \mathrm{~mm}$ reinforcement bars spaced at $150 \mathrm{~mm}$ served as transverse reinforcement in the petal-shaped elements. A special nylon foil called Riverseal 200, produced by Rivertex, which is generally used for life jackets, was used as the pneumatic formwork and for the pneumatic wedges. The pneumatic formwork consisted of two welded flat sheets of foil.

Figure 23 shows the initially flat concrete plate of the demonstration project as well as the finished concrete shell. The transformation process was performed within only 2 hours, after the concrete plate had been allowed to harden for six days. After the transformation had been completed, the post-tensioning cables were anchored and the membrane was deflated.

\section{Conclusion}

Inflatable structures provide a material and labor-saving alternative to conventional formwork systems using plywood and framework. In this paper, a comprehensive historical overview including the most important developments over the past 100 years, as well as recent inventions and research on the topic, is presented. Considering the wide field of application, a classification of the different construction methods into three main groups and four subgroups is provided. The properties of the different applications of the reviewed systems are analyzed, and the results serve as the basis for the application of the existing pneumatic formwork systems and for the development of new systems. Finally, a new construction method is presented and its properties, as well as two large-scale experiments, are described.

\section{Competing Interests}

The authors declare that they have no competing interests.

\section{Acknowledgments}

The presented large-scale experiments were performed in collaboration with the Austrian Society for Construction Technology and conducted as a part of the research project "Free Formed Surfaces out of Concrete." The financial support of all project partners (doka, ÖBB, Asfinag, Strabag, Porr, Alpine, Bilfinger, Habau, Swietelsky, Holcim, Lafarge, Wopfinger, Sika, and Festo) and the Austrian Research Promotion Agency (FFG) is gratefully acknowledged. The processing fee of the paper was paid by the TU Wien.

\section{References}

[1] W. Sobek, "Ultraleichtbau," Stahlbau, vol. 83, no. 11, pp. 784-789, 2014.

[2] Zement+Beton Handels- und Werbeges.m.b.H., Zementerzeugung in Österreich, 4 Auflage, 2012.

[3] Verein Deutscher Zementwerke e. V. (VDZ), Zementindustrie im Überblick, 2014, https://www.vdz-online.de/uploads/ media/Zementindustrie-im-Ueberblick-2014.pdf.

[4] Portland Cement Association-Market Intelligence. World Cement Consumption, 2013.

[5] P. Kumar Metha, Greening of the Concrete Industry for Sustainable Development, Concrete International, 2002.

[6] T. Nose, "Process of Constructing Culverts of Pipes of Concrete," U.S. Patent 1,600,353, 1926.

[7] W. Neff, "Building construction," U.S. Patent 2,270,229, 1941.

[8] W. Neff, "Improved method of erecting shell form concrete structures," U.S. Patent 2,892,239, 1952.

[9] G. Ambrose John and B. Mathews Charles, "Inflatable Core for Use in Casting Hollow Concrete Units," US Patent 2,485,898, 1949. 
[10] F. Leonhardt, "Method of prestressing units with serration," U.S. Patent 2,705,360, 1952.

[11] D. Bini, "Method for erecting structures," US Patent 3,462,521; 1969.

[12] H. Heifetz and Domecrete Building System (Israel), "Bauen + wohnen = construction + habitation = building + home," Internationale Zeitschrift, vol. 26, no. 6, pp. 262-263, 1972.

[13] C. D. MacCracken, "Roof structure of reinforced temperaturehardenable plastic and process making same," U.S. Patent 3,557,515, 1971.

[14] H. Isler, "New materials for shell and spatial structures," in Proceedings of the IASS World Conference, Madrid, Spain, 1979.

[15] F. Prouvost, "Construction of houses or similar buildings by means of an inflatable structure," U.S. Patent 4,094,109, 1978.

[16] Th. T. Thoeny, "Inflatable structures," U.S. Pat. 2007/0094938 A1.

[17] A. Pronk, "The calculation and construction of a 30 meter span ice dome," in Proceedings of the IASS-SLTE Symposium, Shells, Membranes and Spatial Structures: Footprints, Brasilia, Brazil, 2014.

[18] A. Pronk, "The calculation and construction of the highest ice dome-the Sagrada Familia in Ice," in Proceedings of the International Society of Flexible Formwork Symposium (ISOFF '15), Amsterdam, The Netherlands, August 2015.

[19] M. Doerstelmann, J. Knippers, V. Koslowski et al., "ICD/ITKE Research Pavilion 2014-15: fibre placement on a pneumatic body based on a water spider web," Architectural Design, vol. 85, no. 5, pp. 60-65, 2015.

[20] M. Doerstelmann, J. Knippers, and V. Koslowski, "ICD/ITKE research pavilion 2014-15-fibre placement on a pneumatic body based on a water spider web," Architectural Design, vol. 85, no. 5, pp. 60-65, 2015, http://www.monolithic.org/topics/ domes.

[21] Dome Technology LLC, https://www.dometechnology.com.

[22] T. Nose, "Apparatus for construction concrete culverts," U.S. Patent 1,964,386, 1931.

[23] J. Head, No Nails, No Lumber-The Bubble Houses of Wallace Neff, Princeton Architectural Press, New York, NY, USA, 2011.

[24] R. L. Mora, "Inflatable Construction Panels and Method of Making Same," U.S. Patent 3,388,509, 1968.

[25] D. Bini, "A new pneumatic technique for the construction of thin shells. International Association for Shell Structures," in Proceedings of the 1st IASS International Colloquium on Pneumatic Structures, University of Stuttgart, Stuttgart, Germany, May 1967.

[26] D. Bini, “Concrete domes," Official Journal of the Master Builders' Association of New South Wales, vol. 3, no. 7, 1974.

[27] D. Bini, Building with Air, Butler Tanner and Dennis, London, UK, 2014.

[28] A. Pugnale and A. Bologna, "Dante Bini's 'New archtitectural formulae': construction, collapse and domoltion of binishells in Australia 1974-2015," Proceedings of the Society of Architectural Historians Australia and New Zealand, vol. 32, pp. 488-499, 2015.

[29] H. Heifetz, “Inflatable Forms," U.S. Patent 3,643,910, 1972.

[30] E. Ramm and E. Schunk, Heinz Isler Schalen-Katalog zur Ausstellung, vdf Hochschulverlag an der ETH Zürich, 3rd edition, 2002.

[31] D. B. South, "Economics and thin shell dome," Concrete International, vol. 12, no. 8, pp. 18-20, 1990.
[32] N. Neighbor and D. B. South, "An evaluation of the monolithic dome construction method for biological containment structures," Applied Biosafety, vol. 2, no. 1, pp. 39-46, 1997.

[33] R. L. Nicholls, "Air-inflated fabric-reinforced concrete shells," U.S. Patent 4,446,038, 1984.

[34] J. Schlaich and R. Bergermann, "Pneumatische Schalung," Deutsche Patentanmeldung, DE3500153, 1985.

[35] W. Sobek, Auf Pneumatisch Gestützten Schalungen Hergestellte Betonschalen, Ursula Sobek, Stuttgart, Germany, 1987.

[36] T. Kokawa, Building Techniques for Ice Shells as Temporary Structure, Tokai University, Hokkaido, Japan, 2012.

[37] E. Verwimp, T. Tysmans, and M. Mollaert, "Flexible formwork as reinforcement for curved for curved concrete structures," in Proceedings of the IASS Symposium "Beyond the Limits of Men", 2013.

[38] G. Quinn and C. Gengnagel, "A review of elastic grid shells, their erection methods and the potential use of pneumatic formwork," in Proceedings of the 4th International Conference on Mobile, Adaptable and Rapidly Assembled Structures (MARAS '14), pp. 129-144, June 2014.

[39] G. Schieber, V. Koslowski, J. Knippers et al., "Integrated design and fabrication strategies for fibrous structures," in Modelling Behaviour: Design Modelling Symposium, pp. 237-245, Springer, Berlin, Germany, 2015.

[40] SO.CA.P. Srl, http://www.socapsrl.com/.

[41] PIRS S.A.S., http://www.domepirs.com/en/welcome.

[42] Y.S.M. For Building LTD, May 2015, http://ysmforbuilding .com/en/domecrete-domes-building-system.

[43] Concrete Canvas Ltd, http://www.concretecanvas.com.

[44] W. Sobek, "Concrete shells constructed on pneumatic formwork," in Proceedings of the IASS Symposium on Membrane Structures and Space Frames, Shells, Membranes and Space Frames, vol. 1, Osaka, Japan, 1986.

[45] P. C. van Hennik and R. Houtman, "Pneumatic formwork for irregular curved thin shells," in Textile Composites and Inflatable Structures II, E. Oñate and B. Kröplin, Eds., vol. 8 of Computational Methods in Applied Sciences, pp. 99-116, Springer, Berlin, Germany, 2008.

[46] B. Kromoser and J. Kollegger, "Herstellung von schalentragwerken aus Beton mit der 'Pneumatic Wedge Method,' Beton-und Stahlbetonbau, vol. 109, no. 8, pp. 557-565, 2014.

[47] B. Kromoser and J. Kollegger, "Application areas for pneumatic forming of hardened concrete," Journal of the International Association for Shell and Spatial Structures, vol. 56, no. 3, pp. 187-198, 2015.

[48] B. Kromoser and J. Kollegger, "Pneumatic forming of hardened concrete-building shells in the 21st century," Structural Concrete, vol. 16, no. 2, pp. 161-171, 2015. 

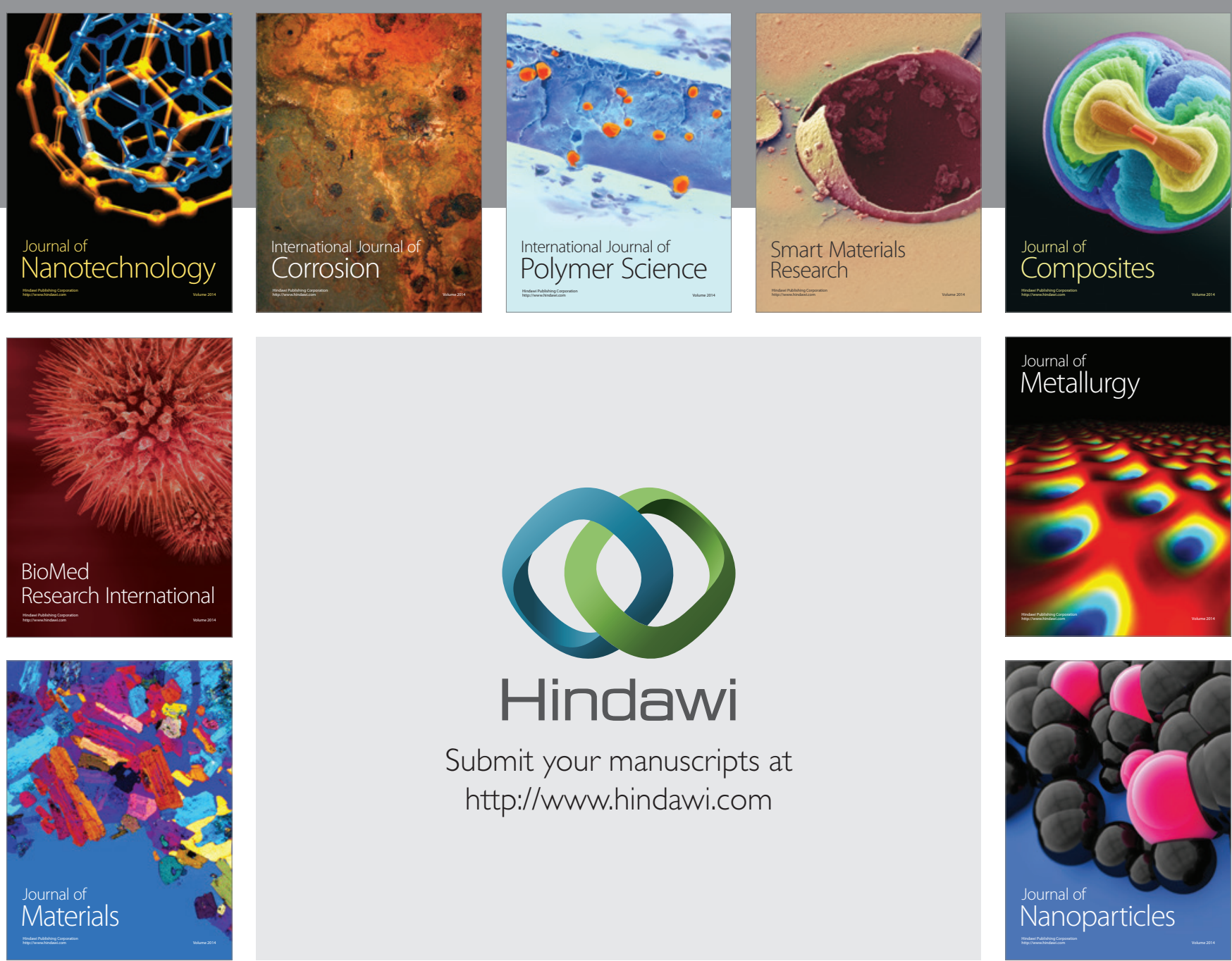

\section{Hindawi}

Submit your manuscripts at

http://www.hindawi.com

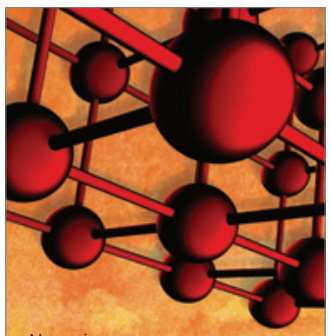

Materials Science and Engineering
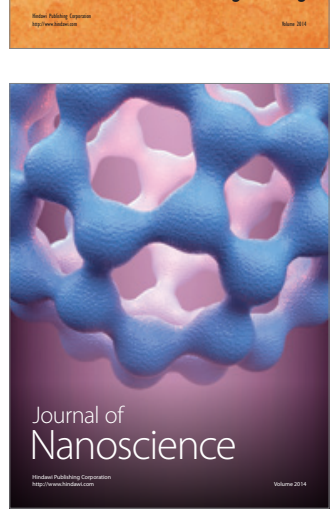
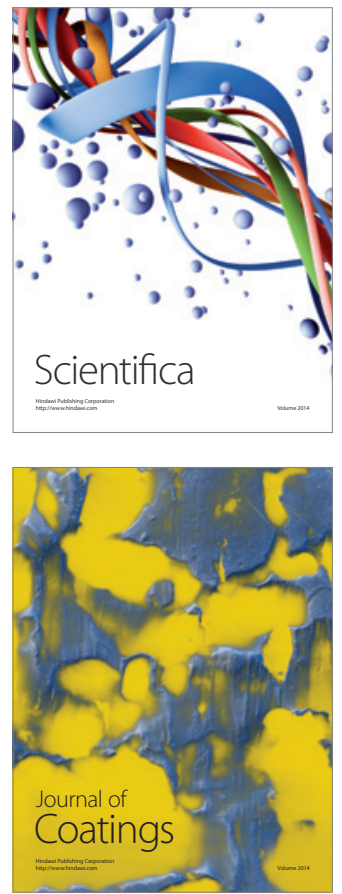
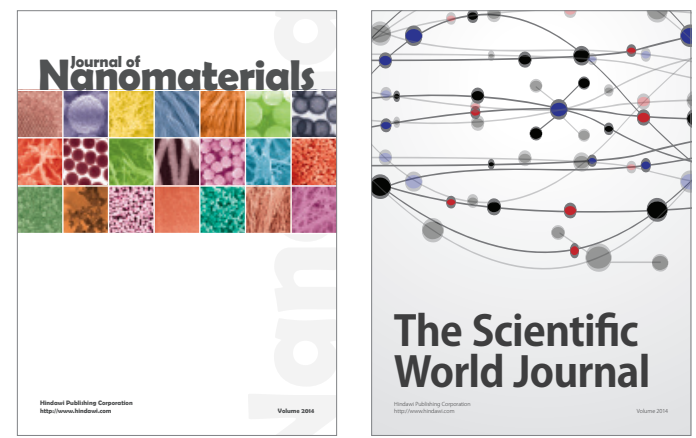

The Scientific World Journal
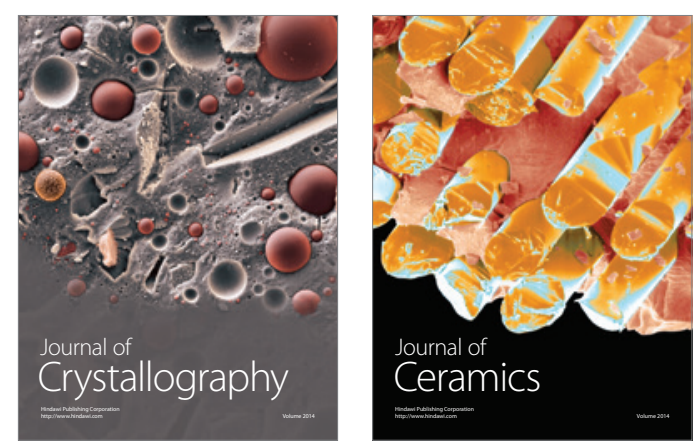
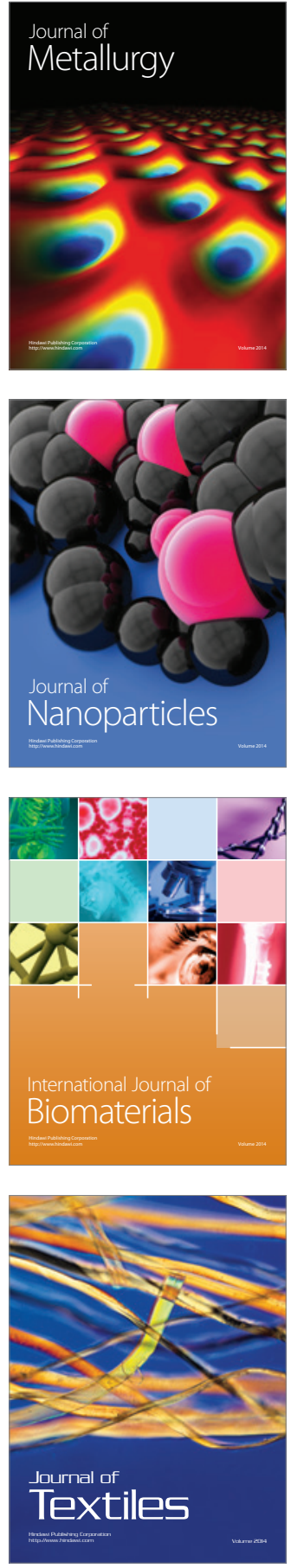